\section{Prevalence and Associated Factors of Stunting among 6-59 Months Children in Pastoral Community of Korahay Zone, Somali Regional State, Ethiopia 2016}

Sisay Shine ${ }^{*}$, Frew Tadesse, Zemenu Shiferaw, Lema Mideksa and Wubarege Seifu

College of Medicine and Health Science, Public Health Department, Epidemiology and Biostatistics Unit, Jig-Jiga University, Jig-Jiga, Ethiopia

"Corresponding author: Sisay shine (MPH), Lecturer of public health, College of Medicine and Health Science, Public Health Department, Epidemiology and Biostatistics Unit, Jig-Jiga University, Jig-Jiga, Ethiopia, Tel: +251-921-646475; E-mail: sisayask@gmail.com

Received date: February 03, 2017; Accepted date: March 07, 2017; Published date: March 14, 2017

Copyright: ( 2017 Shine, et al. This is an open-access article distributed under the terms of the Creative Commons Attribution License, which permits unrestricted use, distribution, and reproduction in any medium, provided the original author and source are credited.

\begin{abstract}
Back ground: Stunting is one of the most important public health problems in Ethiopia with an estimated $44.4 \%$ of children less than five years of age being stunted. Thus, this study aimed to assess prevalence and associated factors of stunting among 6-59 months children in pastoral community of Korahay Zone, Somali Regional State, Ethiopia.
\end{abstract}

Objective of the study: To assess prevalence and associated factors of stunting among 6-59 months children in pastoral community of Korahay Zone, Somali Regional State, Ethiopia, 2016.

Methods: Community based cross sectional study design was done among 770 children in pastoral community of Korahay Zone. Systematic sampling techniques were used to select households and took child-mother pair from each selected households. Data was collected using pre-tested and structured questionnaire. Odd ratios with $95 \%$ confidence interval were used to assess level of significance.

Result: Prevalence of stunting among 6-59 months age children was 31.9\%. Sex (AOR: 1.47, 95\%Cl 1.02, 2.11), age (AOR: $2.10,95 \% \mathrm{Cl} 1.16,3.80)$, maternal education (AOR: 3.42, 95\%Cl 1.58, 7.41), maternal occupation (AOR: $3.10,95 \% \mathrm{Cl} 1.85,5.19)$, monthly income (AOR: 1.47, 95\%Cl 1.03, 2.09), postnatal care visits (AOR: $1.59,95 \% \mathrm{Cl}$ $1.07,2.37$ ), source of water (AOR: $3.41,95 \% \mathrm{Cl} 1.96,5.93)$, toilet availability (AOR: $1.71,95 \% \mathrm{Cl} 1.13,2.58$ ), first milk feeding (AOR: $3.37,95 \% \mathrm{Cl} 2.27,5.02$ ) and bottle feeding (AOR: $2.07,95 \% \mathrm{Cl} 1.34,3.18$ ) were significant predictors of stunting.

Conclusion and recommendations: Prevalence of stunting among 6-59 months children was high 31.9\%. Lack of maternal education, not feeding first milk, unsafe water supply, unavailability of toilet facilities and bottle feeding can increase the risk of stunting. So, educating mothers on child feeding practice, sanitation and important of first milk can reduce stunting.

Keywords: Stunting; Socio-demographic; Environmental; Dietary; Children; Korahay; Ethiopia

\section{Introduction}

Stunting is referred to as being low-height-for-age (HAZ), less than minus two standard deviations (SD) of the new WHO Growth Standard, as it reflects a process of failure to reach linear growth potential as a result of prolonged or repeated episodes of under nutrition starting before birth [1]. It is an indicator of chronic malnutrition [1]. Globally, $34 \%$ or one in four children under-5 years old are stunted (26 per cent in 2011). An estimated 165 million (80\%) of the world's stunted children live in just 14 countries [2]. Africa and Asia continents have the highest stunting with more than $90 \%$ of the world stunted children living in these continents [3]. About 182 million (32.5\%) children in developing countries and $42 \%$ of children in sub-Saharan Africa were stunted [4,5].

Different studies conducted in Ethiopia indicated that stunting is one of the most important public health problems in the country [6-10] with different contributing factors such as sex $[7,10,11]$, age of child [9], maternal education $[6,12]$, father education [8], maternal occupation [12,13], household income [6,9,14], antenatal care service utilization $[7,12,14]$, source of water [15], first milk feeding [16] and methods of feeding $[13,16]$.

Ethiopia's aim is to contribute to the national target of reducing stunting among children under the age of five in selected regions, by reaching 1.5 million stunted children and reduce the prevalence of stunting by up to $26 \%$ between 2015 and 2020 . The initiative plans to enhance and scale-up high impact feasible Community Based Nutrition programs with the promotion of complementary feeding and dietary diversity at the household level. This will enable children at six months of age to be introduced to nutritionally adequate and safe solid foods with continued breast feeding. The interventions will be implemented and only focused on 150 districts with a total coverage of 1.5 million stunted children living in four agrarian regions [17].

It is important to extend the intervention activity to pastoral and agro pastoral regions like Somali region at which more $37.97 \%$ of the population was pastoralist and is one of the most underserved regions in terms of access to essential services and characterized by a high level of child malnutrition, food insecurity and vulnerable livelihoods [18]. According to the 2011 demographic and health survey of Ethiopia, the 
Citation: Shine S, Tadesse F, Shiferaw Z, Mideksa L, Seifu W (2017) Prevalence and Associated Factors of Stunting among 6-59 Months Children in Pastoral Community of Korahay Zone, Somali Regional State, Ethiopia 2016. J Nutr Disorders Ther 7: 208. doi: 10.4172/2161-0509.1000208

Page 2 of 8

prevalence of stunting in the region was very high 33\% [6]. Despite few local studies conducted in different parts of the region, no previous study attempts to address the magnitude and shortcoming of causes of stunting among the pastoral community of Korahay Zone. Therefore, determining magnitude and identifying risk factors of stunting in the study area is important to guide public health planners, policy makers and implementers to plan and design appropriate intervention strategies in order to enhance nutritional status of children.

\section{Methods}

\section{Study design, period and area}

Community based cross sectional quantitative study design was used to assess prevalence and associated factors of stunting among 6-59 months age children of pastoral community of Korahay Zone Somali Regional State, Ethiopia 2016.

\section{Source and study population}

The source population was all 6-59 months age children and their mothers in Korahay Zone, Somali Regional State. The study population was 6-59 months age children living in the selected three woredas of Korahay Zone, Somali Regional State.

\section{Inclusion and exclusion criteria}

Inclusion criteria: Children 6-59 months age who lived with their mothers and whose mothers were available in the selected households.

Exclusion criteria: Both children under-five years of age and whose mothers were critically ill during data collection were not selected.

Children less than 6 month's age and greater than 59 months age were excluded from the study.

\section{Sample size determination}

Sample size was determined based on the formula used to estimate single population proportion assuming that $34.5 \%$ of under-five children from Dola Ado pastoral community study were stunted [11]. And 5\% margin of error with $95 \%$ confidence level with anticipated $10 \%$ non-response rate.

$$
\begin{aligned}
& n=\frac{\left(Z^{\alpha} / 2\right)^{2} P(1-P)}{d^{2}} \\
& n=\frac{(1.96)^{2}(0.345)(0.655)}{0.05^{2}}=347
\end{aligned}
$$

After adjusting for non-response rate of $10 \%$ and design affect of 2 the final required sample size was 770 mother-child pair.

\section{Sampling techniques and procedures}

Multi-stage sampling technique was used to select the study population. From a total of six woredas found in the Korahay zone, three woredas were selected randomly. From each selected woreda, 3 kebeles were selected through random sampling techniques. Prior to the actual data collection, census was conducted in each selected kebeles to know the eligible households. Then, households were selected by using systematic random sampling techniques and took child-mother pair from each selected household until the required sample size was fulfilled; the starting household was selected by using lottery method.

\section{Data collection methods and instrument}

Structured questionnaire adapted from UNICEF and after reviewing different literatures of similar studies and anthropometric measurements were used for the collection of quantitative data. Data on stunting (chronic malnutrition) and demographic, socio-economic, environmental healthcare and dietary factors among 6-59 months age children were collected via interview. Sixteen data collection team members, ten data collectors, three anthropometric measurement recorders and three supervisors were involved in the data collection. English version questionnaire was translated to Somali language and again translated back to English by experts who are fluent in both languages to check consistency.

\section{Anthropometry measurements}

Height: Length measurement for children below 24 months was taken in laying down or recumbent position and standing height was taken for children 24-59 months age and the measurement was taken to the nearest $0.1 \mathrm{~cm}$ using Short's Height Measuring Board, with the subjects shoeless [19,20].

Age: Childrens' age was collected from the mother and confirmed by using birth certificate or vaccination cards and also used or a "localevents calendar" $[19,20]$.

\section{Operational definition}

Stunting: Children whose height-for-age Z-score is below minus two standard deviations (-2 SD) from the median of the WHO reference population are considered short for their age (stunted) [1].

Duration of breastfeeding: The number of months of breastfeeding among children.

Complementary feeding: The child receives both breast milk and breast milk substitute foods.

Low income: Households with monthly income below mean income of the sample 1,500 ETB.

\section{Study variables}

Stunting was an outcome variable and socio economicdemographic, environmental, health care and dietary factors were independent variables.

Socio-demographic factors: sex, age, birth order, birth interval, mother education, father education, mother occupation, father occupation, household monthly income.

Environmental factors: source of drinking water, toilet availability.

Health care factors: child weight and size, mother place of delivery, child immunization, child diarrheal status, mother antenatal care visits, and mother postnatal care visits.

Dietary factors: breast feeding, time of initiation of breast feeding, first milk feeding duration of breast feeding, age for introduction of complementary food, method of feeding. 
Citation: $\quad$ Shine S, Tadesse F, Shiferaw Z, Mideksa L, Seifu W (2017) Prevalence and Associated Factors of Stunting among 6-59 Months Children in Pastoral Community of Korahay Zone, Somali Regional State, Ethiopia 2016. J Nutr Disorders Ther 7: 208. doi: $10.4172 / 2161-0509.1000208$

Page 3 of 8

\section{Data processing and analysis}

Data was entered by using EPI INFO 3.5.1 version computer software package for editing, cleaning, coding, and checking completeness and consistency. Finally, data was exported to SPSS window version 16 for data management and analysis. Anthropometric indices were calculated using WHO Anthro2007 software (version 2.0.4). Association and correlation of the variables were computed using OR and 95\% CI. Both bivariate and multivariate logistic regression analysis were used to identify the predictors of stunting. Variables with $95 \%$ confidence interval and $\mathrm{P}$ value at $<0.2$ during the bivariate analysis were included in the multivariate logistic regression analysis to see the relative effect of confounding variables. Adjusted odd ratios with $95 \%$ confidence interval were calculated and P-value less than 0.05 were considered as statistically significant. Finally, data was displayed by tables, graphs and statements.

\section{Data quality management}

The questionnaire was prepared originally in English and translated to Somali language and back to English to keep consistency of the questioner. Pre-test of questionnaire were done before the actual data collection to estimate time needed and some modifications were made on the basis of the findings. The interviewers, anthropometric recorders and supervisors were trained on data collection and measurement techniques for three days. On daily basis, collected information was reviewed and possible errors were returned to the data collectors for correction. Data validity and reliability was maintained through close supervision of enumerators by the principal investigator.

\section{Results}

A total of 745 children aged 6-59 months participated in the study with the response rate of $96.75 \%$. From the total respondents, 442 (59.3) were female, 208 (27.9\%) found in the age group of 12-23 months, mean age of children 25 months with the SD of \pm 13.59 months, 736 (98.8\%) were Muslim followers in religion and 724 (97.2\%) were Somali in ethnic group.

\section{Magnitudes of stunting among 6-59 months children}

From the total children of 6-59 months age in the study area 238 (31.9\%) were stunted (<-2SD), out of which 144 (19.3\%) were moderately stunted $(-2<\mathrm{SD}<-3)$ and $94(12.6 \%)$ were severely stunted
$(<-3 \mathrm{SD})$ (Figure 1). The prevalence was $11.3 \%$ in children age group of 12-23 months (Figure 2).

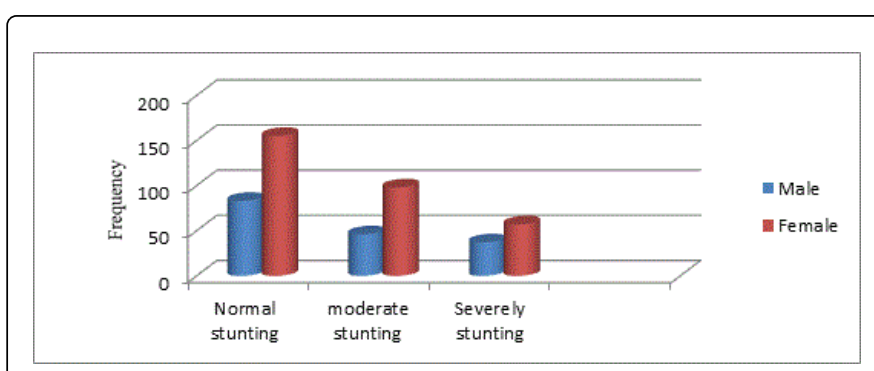

Figure 1: Prevalence of stunting with sex among children 6-59 months in pastoral community of Korahay Zone, Somali Regional State, Ethiopia, 2016.

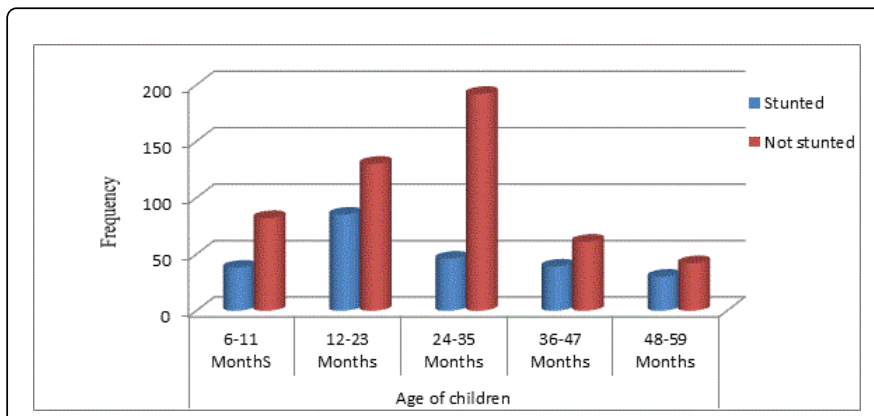

Figure 2: Prevalence of stunting with age groups among children 6-59 months in pastoral community of Korahay Zone, Somali Regional State, Ethiopia, 2016.

\section{Factors associated with stunting}

Socio-demographic factors: from socio-demographic variables sex of child (AOR: 1.47, 95\% CI 1.02, 2.11), age of child (AOR: $2.10,95 \%$ CI 1.16, 3.80), mother's education can read and write (AOR: $3.04,95 \%$ CI 1.40, 6.59), can't read and write (AOR: 3.42, 95\% CI 1.58, 7.41), primary school (AOR: 7.18, 95\% CI 2.05, 25.13), mother occupation (AOR: 3.10, 95\% CI 1.85, 5.19) and household monthly income (AOR: $1.47,95 \%$ CI $1.03,2.09)$ showed significant association with stunting (Table 1).

\begin{tabular}{|c|c|c|c|c|}
\hline \multirow{2}{*}{ Socio-demographic variable } & \multicolumn{2}{|l|}{ Stunting } & \multirow{2}{*}{ COR $(95 \% \mathrm{CI})$} & \multirow{2}{*}{ AOR $(95 \% \mathrm{Cl})$} \\
\hline & Yes (\%) & No $(\%)$ & & \\
\hline \multicolumn{5}{|l|}{ Sex of child } \\
\hline Male & $83(11.1)$ & $220(29.5)$ & $1.43(1.04,1.97)$ & $1.47(1.02,2.11)^{\star}$ \\
\hline Female & $155(20.8)$ & $287(38.6)$ & 1.00 & 1.00 \\
\hline \multicolumn{5}{|l|}{ Children's age in month } \\
\hline $6-11$ & $38(5.1)$ & $79(10.6)$ & 1.00 & 1.00 \\
\hline $12-23$ & $78(11.3)$ & $130(17.4)$ & $0.80(0.50,1.29)$ & $1.60(0.67,2.02)$ \\
\hline $24-35$ & $46(6.1)$ & $139(18.7)$ & $1.45(0.87,2.42)$ & $2.10(1.16,3.80)^{*}$ \\
\hline
\end{tabular}


Citation: $\quad$ Shine S, Tadesse F, Shiferaw Z, Mideksa L, Seifu W (2017) Prevalence and Associated Factors of Stunting among 6-59 Months Children in Pastoral Community of Korahay Zone, Somali Regional State, Ethiopia 2016. J Nutr Disorders Ther 7: 208. doi: 10.4172/2161-0509.1000208

Page 4 of 8

\begin{tabular}{|c|c|c|c|c|}
\hline $36-47$ & $42(5.3)$ & $86(11.5)$ & $0.99(0.58,1.68)$ & $1.65(0.87,3.12)$ \\
\hline $48-59$ & $34(4.1)$ & $73(9.9)$ & $1.03(0.59,1.81)$ & $1.59(0.81,3.12)$ \\
\hline \multicolumn{5}{|l|}{ Mother's education } \\
\hline Can read and write & $125(16.8)$ & $222(29.8)$ & $1.37(0.73,2.55)$ & $3.04(1.40,6.59)^{*}$ \\
\hline Can't read and write & $76(10.2)$ & $219(29.4)$ & $2.21(1.17,4.18)$ & $3.42(1.58,7.41)^{*}$ \\
\hline Primary (1-8) school & $6(0.8)$ & $26(3.5)$ & $3.33(1.15,9.64)$ & $7.18(2.05,25.13)^{\star}$ \\
\hline Secondary (9-12) & $11(1.5)$ & $14(1.9)$ & $0.98(1.37,2.61)$ & $1.62(0.54,4.84)$ \\
\hline Above secondary & $20(2.6)$ & $26(3.5)$ & 1.00 & \\
\hline \multicolumn{5}{|l|}{ Father's education } \\
\hline Can read and write & $129(17.3)$ & $292(39.2)$ & $1.25(1.05,1.85)$ & \\
\hline Can't read and write & $28(3.8)$ & $72(9.7)$ & $1.42(1.02,2.45)$ & \\
\hline Primary (1-8) & $11(1.5)$ & $15(2.0)$ & $0.75(1.32,1.75)$ & \\
\hline Secondary (9-12) & $16(2.1)$ & $30(4.0)$ & $0.84(1.52,2.06)$ & \\
\hline Above secondary & $54(7.2)$ & $98(13.2)$ & 1.00 & \\
\hline \multicolumn{5}{|l|}{ Mother's occupation } \\
\hline House Wife & $189(25.3)$ & $325(43.6)$ & 1.00 & 1.00 \\
\hline Government employee & $31(4.3)$ & $134(18.0)$ & $2.51(1.64,3.86)$ & $3.10(1.85,5.19)^{\star *}$ \\
\hline Self-employer & $18(2.3)$ & $48(6.5)$ & $1.55(0.88,2.74)$ & $1.31(0.68,2.54)$ \\
\hline \multicolumn{5}{|l|}{ Father's occupation } \\
\hline Farmer & $100(13.4)$ & $210(28.2)$ & 1.00 & \\
\hline Government employee & $72(9.6)$ & $148(19.9)$ & $0.98(0.68,1.42)$ & \\
\hline Non-government employee & $17(2.3)$ & $35(4.7)$ & $0.98(0.52,1.83)$ & \\
\hline Merchant and Self-employee & $49(6.6)$ & $144(15.3)$ & $1.11(0.74,1.67)$ & \\
\hline \multicolumn{5}{|c|}{ Household monthly income in ETB } \\
\hline Less than 1,760 & $103(13.8)$ & $273(36.6)$ & $1.53(1.12,2.09)$ & $1.47(1.03,2.09)^{*}$ \\
\hline 1,760 and more & $135(18.1)$ & $234(31.5)$ & 1.00 & 1.00 \\
\hline
\end{tabular}

Table 1: Association of stunting with socio-demographic determinants among 6 to 59 months children in pastoral community of Korahay Zone, Somali Regional State, Ethiopia, 2016.

Healthcare and environmental factors: from health care and environmental factors such as mother attending PNC service (AOR: $1.59,95 \%$ CI 1.07, 2.37), unprotected well as source water (AOR: 3.41 , 95\% CI 1.96, 5.93) and availability toilet facility (AOR: 1.71, 95\% CI

$1.13,2.58)$ showed significant association with stunting. But birth order of child (AOR: $4.46,95 \%$ CI $0.38,51.49$ ) and preceding birth interval of child (AOR: 033, 95\% CI 0.03, 3.81) didn't show significant association with stunting (Table 2).

\begin{tabular}{|l|l|l|l|l|}
\hline \multirow{2}{*}{ Healthcare and environmental variable } & \multicolumn{2}{|l|}{ Stunting } & \multirow{2}{*}{ COR (95\% Cl) } & AOR (95\%Cl) \\
\cline { 2 - 4 } & Yes (\%) & No (\%) & & \\
\hline No. of ANC visits of mother & & & $0.96(0.40,2.31)$ & \\
\hline None & $30(4.0)$ & $77(10.3)$ & \\
\hline
\end{tabular}


Citation: Shine S, Tadesse F, Shiferaw Z, Mideksa L, Seifu W (2017) Prevalence and Associated Factors of Stunting among 6-59 Months Children in Pastoral Community of Korahay Zone, Somali Regional State, Ethiopia 2016. J Nutr Disorders Ther 7: 208. doi: 10.4172/2161-0509.1000208

Page 5 of 8

\begin{tabular}{|c|c|c|c|c|}
\hline 1 & $39(5.2)$ & $80(10.7)$ & $0.77(0.33,1.81)$ & \\
\hline $2-3$ & $160(21.5)$ & $326(43.9)$ & $0.76(0.35,1.68)$ & \\
\hline 4 and more & $9(1.2)$ & $24(3.2)$ & 1.00 & \\
\hline \multicolumn{5}{|l|}{ PNC visits of Mother } \\
\hline Yes & $104(13.1)$ & $144(19.3)$ & 1.00 & 1.00 \\
\hline No & $134(18.8)$ & $363(48.8)$ & $1.96(1.42,2.70)$ & $1.59(1.07,2.37)^{\star}$ \\
\hline \multicolumn{5}{|c|}{ Mother's age at Pregnancy } \\
\hline Less than 20 years & $85(11.4)$ & $160(21.5)$ & $0.98(0.56,1.72)$ & \\
\hline 20 to 35 years & $129(17.3)$ & $301(40.4)$ & $1.23(0.71,2.08)$ & \\
\hline More than 35 years & $24(3.2)$ & $46(6.2)$ & 1.00 & \\
\hline \multicolumn{5}{|c|}{ Mother's place of delivery } \\
\hline Public facility & $79(10.6)$ & $151(20.3)$ & 1.00 & \\
\hline Private facility & $4(0.5)$ & $12(1.6)$ & $1.57(0.49,5.03)$ & \\
\hline At home & $155(20.8)$ & $344(46.2)$ & $1.16(0.83,1.62)$ & \\
\hline \multicolumn{5}{|l|}{ Birth order of child } \\
\hline 1 & $87(11.7)$ & $123(16.6)$ & 1.00 & 1.00 \\
\hline $2-3$ & $111(14.9)$ & $275(36.9)$ & $1.75(1.23,2.49)$ & $4.46(0.38,51.49)$ \\
\hline 4 and above & $40(5.3)$ & $109(14.6)$ & $1.93(1.22,3.04)$ & $5.49(0.47,64.22)$ \\
\hline \multicolumn{5}{|c|}{ Preceding birth interval } \\
\hline Less than 24 months & $151(20.3)$ & $378(50.7)$ & $1.68(1.21,2.35)$ & $0.33(0.03,3.81)$ \\
\hline More than 24 months & $87(11.6)$ & $129(17.4)$ & 1.00 & 1.00 \\
\hline \multicolumn{5}{|c|}{ Took any form of vaccination } \\
\hline Yes & $153(20.5)$ & $348(46.7)$ & 1.00 & \\
\hline No & $85(11.4)$ & $159(21.4)$ & $0.82(0.59,1.14)$ & \\
\hline \multicolumn{5}{|c|}{ Diarrheal status of children } \\
\hline Yes & $48(6.4)$ & $96(12.9)$ & $0.93(0.63,1.36)$ & \\
\hline No & $190(25.5)$ & $411(55.2)$ & 1.00 & \\
\hline \multicolumn{5}{|c|}{ Sources of drinking water } \\
\hline Private tap & $71(9.5)$ & $84(11.3)$ & 1.00 & 1.00 \\
\hline Public tap & $83(11.1)$ & $177(23.8)$ & $1.80(1.20,2.72)$ & $1.35(0.84,2.17)$ \\
\hline Protected well & $26(3.5)$ & $62(8.3)$ & $2.02(1.16,3.53)$ & $1.76(0.92,3.37)$ \\
\hline Unprotected well & $58(7.8)$ & $184(24.7)$ & $2.68(1.74,4.13)$ & $3.41(1.96,5.93)^{\star *}$ \\
\hline \multicolumn{5}{|c|}{ Toilet facility availability } \\
\hline Yes & $176(23.6)$ & $307(41.2)$ & 1.00 & 1.00 \\
\hline No & $62(8.3)$ & $200(26.9)$ & $1.85(1.32,2.60)$ & $1.71(1.13,2.58)^{*}$ \\
\hline
\end{tabular}


Citation: $\quad$ Shine S, Tadesse F, Shiferaw Z, Mideksa L, Seifu W (2017) Prevalence and Associated Factors of Stunting among 6-59 Months Children in Pastoral Community of Korahay Zone, Somali Regional State, Ethiopia 2016. J Nutr Disorders Ther 7: 208. doi: 10.4172/2161-0509.1000208

Page 6 of 8

\section{* Significant at $\mathrm{P}<0.05$ ** Significant at $\mathrm{P}<0.001$}

Table 2: Association of stunting with healthcare and environmental factors among 6 to 59 months children in pastoral community of Korahay Zone, Somali Regional State, Ethiopia, 2016.

Dietary factors: dietary factors such as child fed first milk (AOR: children at which complementary food started before six months 3.37, 95\% CI 2.27, 5.02) and bottle feeding (AOR: 2.07, 95\% CI 1.34, (AOR: 095, 95\% CI 0.63, 1.45) and after six months (AOR: 1.19, 95\% 3.18) showed significant association with stunting. But time for CI $0.63,2.23$ ) didn't show significant association with stunting (Table initiation of breast feeding (AOR: $1.25,95 \%$ CI $0.86,1.82$ ) and age of 3 ).

\begin{tabular}{|c|c|c|c|c|}
\hline \multirow{2}{*}{ Dietary variable } & \multicolumn{2}{|l|}{ Stunting } & \multirow{2}{*}{$\operatorname{COR}(95 \% \mathrm{Cl})$} & \multirow{2}{*}{ AOR $(95 \% \mathrm{Cl})$} \\
\hline & Yes (\%) & No (\%) & & \\
\hline \multicolumn{5}{|l|}{ Time for initiation of $B F$} \\
\hline Within 1 hour & $110(14.8)$ & $182(24.4)$ & 1.00 & 1.00 \\
\hline Within 24 hours & $128(17.1)$ & $325(43.7)$ & $1.54(1.12,2.10)$ & $1.25(0.86,1.82)$ \\
\hline \multicolumn{5}{|l|}{ Child fed first milk } \\
\hline Yes & $186(17.2)$ & $299(40.1)$ & 1.00 & 1.00 \\
\hline No & $52(14.7)$ & $208(27.9)$ & $3.40(2.39,4.88)$ & $3.37(2.27,5.02)^{\star *}$ \\
\hline \multicolumn{5}{|l|}{ Duration of breast feeding } \\
\hline Less than 12 months & $128(20.0)$ & $274(36.8)$ & $1.24(0.91,1.69)$ & $1.17(0.82,1.68)$ \\
\hline More than 12 months & $110(11.9)$ & $233(31.3)$ & 1.00 & 1.00 \\
\hline \multicolumn{5}{|l|}{ Complementary food Started } \\
\hline At 6 month & $71(9.5)$ & $123(16.5)$ & 1.00 & 1.00 \\
\hline Before 6 month & $142(19.1)$ & $316(42.4)$ & $1.30(0.92,1.83)$ & $0.95(0.63,1.45)$ \\
\hline After 6 month & $25(3.3)$ & $68(9.2)$ & $1.57(0.91,2.71)$ & $1.19(0.63,2.23)$ \\
\hline \multicolumn{5}{|l|}{ Cup for feeding } \\
\hline Yes & $199(26.7)$ & $411(55.2)$ & $0.84(0.55,1.12)$ & \\
\hline No & $39(5.2)$ & $96(12.9)$ & 1.00 & \\
\hline \multicolumn{5}{|l|}{ Spoon for feeding } \\
\hline Yes & $10(1.3)$ & $16(2.2)$ & $0.74(0.33,1.61)$ & \\
\hline No & $228(30.6)$ & $491(65.9)$ & 1.00 & \\
\hline \multicolumn{5}{|l|}{ Hand for feeding } \\
\hline Yes & $37(5.0)$ & $73(9.8)$ & $0.91(0.60,1.40)$ & \\
\hline No & $201(26.9)$ & $434(58.3)$ & 1.00 & \\
\hline \multicolumn{5}{|l|}{ Bottle for feeding } \\
\hline Yes & $112(15.0)$ & $282(37.9)$ & $0.71(0.52,0.97)$ & $2.07(1.34,3.18)^{\star *}$ \\
\hline No & $126(16.9)$ & $225(30.2)$ & 1.00 & 1.00 \\
\hline
\end{tabular}

Table 3: Association of stunting with dietary factors among 6 to 59 months children in pastoral community of Korahay Zone, Somali Regional State, Ethiopia, 2016. 


\section{Discussion}

In this study, the prevalence of stunting was $31.9 \%$. This is congruent with previous study reports in China [21], was 27\%, Indonesia [22], was $29 \%$, Uganda [20], was $33.3 \%$, Somalia [23], was $31 \%$ and in different part of Ethiopia [6,9-12]. However, the findings of this study was higher than the report in Brazil [24], was 15.5\%, Iran [25], was $9.53 \%$ and pastoral community of Tanzania [26], was $14 \%$. These variations might be due to the area was one of the most underserved area in terms of access to health services and characterized by high level of food insecurity, vulnerable livelihood and recurrent episodes of drought. However, prevalence of stunting in this study was lower than the report in Delhi [27], was $42.2 \%$, India [28], was $49.6 \%$, Nigeria [29], was $38.7 \%$, Kenya [30], was $45.9 \%$, and different part of Ethiopia [7,14,16]. These might be due to deference in cultural diet of pastoral community which is typically protein rich food like milk and meat.

This study revealed that boys (AOR: $1.47,95 \%$ CI 1.02, 2.11) were more likely to be stunted compared with girls. This was consistent with the reports in Iran [25], Indonesia [22], Somalia [23], Democratic Republic of Congo [31], Sub-Sahara Africa countries [32] and Ethiopia $[6,7,10,16]$. In contrast study conducted in India [33] showed that girls were more stunted than boys. This variation might be due to unmeasured factors on care-giving behaviours by the sex preference of mothers. However, Studies conduct in China [21], Cambodia [34], and in Ethiopia [15] suggested that there was no difference in prevalence of stunting by sex of the children this might be due to the variation of study population.

In this study, child at age category of 24-35 (AOR: 2.10, 95\% CI 1.16, 3.80) were more likely stunted compared with 6-11months. It was consistent with a previous study done in Ethiopia [9]. This could be because; it was the critical age for children to shift from breast milk feed to other food.

This study indicated that maternal educational status was inversely associated with stunting. This was consistent with the report in Nepal [35], India [28], Iran [25], Nigeria [36], Tanzania [26], Kenya [37], Somalia [23], and Ethiopia [6,12]. Maternal education increase knowledge about their children's health and nutrition, which can have impact on prevention of stunting.

Children from government employee's mothers (AOR: 3.10, 95\% CI $1.85,5.19)$ were more likely to develop stunting than house wife mothers. It was consistent with the study done in Nepal [35] and Ethiopia $[6,12]$. This might be due to housewife mothers could get more time to care their children.

This study indicated that children living in households that have low monthly income (AOR: $1.47,95 \%$ CI 1.03, 2.09) were more likely to develop stunting than children living in high monthly income. It was consistent with the study done Nepal [35], India [28], Iran [25], Indonesia [22], and Ethiopia $[6,9,12,14]$. This could be due to the fact that, low income levels of households limits the kinds and the amounts of food available for consumption and will not have access to health care and get quality food.

In the study area, postnatal visits (AOR: $1.59,95 \%$ CI 1.07, 2.37) showed significant association with stunting. But a study done in Northeastern Ethiopia [10] showed that postnatal visits didn't show significant association with stunting. This variation might be due to the difference in population on the acceptability of health service provided in the area.
In this study using unprotected well (AOR: 3.41, 95\% CI 1.96, 5.93) as source of water supply showed significant association with stunting. This was consistent with the report in Guatemala [38], Nigeria [36], and Ethiopia [15]. In contrary, studies in Iran [25], Cambodia [34], and Ethiopia [12] revealed that availability of safe drinking water had no associated with stunting. This variation might be due to the difference in sampling techniques and study population.

Availability of toilet facilities (AOR: $1.71,95 \%$ CI 1.13, 2.58) showed association with risk of stunting in the study. It was consistent with the study done in Nigeria [36] and Ethiopia [12]. Toilet availability leads the community to have better sanitation that lowers the risk of infection among the children.

Children who were not fed first milk (AOR: 3.37, 95\% CI 2.27, 5.02) had higher occurrence of stunting than who fed first milk. It was consistent with the study done in India [28], Nepal [35], and Ethiopia [16]. First milk can protect children from different diseases such as diarrhea and pneumonia.

Feeding children by using bottle increase the risk of stunting in the study area. It was consistent with the studies done in Ethiopia [13,16]. In contrary, another study done in Ethiopia [9] showed that bottle feeding had no association with stunting. Bottle feeding can increase repeated infection of children by diarrhea due to bottle is easily contaminated.

In this study, we have limitations that should be noted. Use of crosssectional study may not create true causal relationship between stunting and its risk factors. Qualitative data were not included to explore some associated factors and to triangulate the finding of the quantitative study through qualitative data.

\section{Conclusion and Recommendation}

Prevalence of stunting among under-five children in the study area is still high $31.9 \%$. Sex of child, age of child, maternal education, maternal occupation, household monthly income, postnatal care visit by mothers, source of drinking water, toilet availability, children feeding first milk and bottle feeding were risk factors of stunting. So, educating mothers on child feeding practice, sanitation and important of first milk can reduce stunting.

\section{Declarations}

\section{Ethical approval and consent to participate}

This study was carried out after getting ethical clearance from JigJiga University research ethics review committee. Data collection was carried out after receiving ethical clearance letter from the regional health bureau and administration office. Informed verbal consent was obtained from each study participant prior to data collection.

\section{Acknowledgements}

We would like to thank Regional Health Bureau and Zonal Health Office heads for their collaboration during conducting this research. Our gratitude also goes to our data collectors and study participants for their willingness to participate in the study. At last but not least, we would like to forward my special thank and sincere appreciations to our friends who gave advice and comment throughout the whole research project activities. 
Citation: Shine S, Tadesse F, Shiferaw Z, Mideksa L, Seifu W (2017) Prevalence and Associated Factors of Stunting among 6-59 Months Children in Pastoral Community of Korahay Zone, Somali Regional State, Ethiopia 2016. J Nutr Disorders Ther 7: 208. doi: 10.4172/2161-0509.1000208

Page 8 of 8

\section{References}

1. SCUK: A life free from hunger: Tackling child malnutrition London (2012) Save the Children Fund UK.

2. J.Badham, L.Sweet (2010) Stunting: An Overview. SIGHT AND LIFE Magazine 3: 40-47.

3. UNICEF: Improved child nutrition the achievable imperative for global progress (2013) United Nations Plaza, New York.

4. UNDP (2012) Children Malnutrition and Horizontal Inequalities in SubSaharan Africa.

5. Onis M, Blossner M, Borghi E (2011) Prevalence and trends of stunting among pre-school children 1990-2020. Public Health Nutr 15:142-148.

6. CSA (2011) Demographic and health survey Addis Ababa, Ethiopia.

7. Asfaw M, Wondaferash, Taha M, Dube L (2015) Prevalence of undernutrition and associated factors among children aged between six to fifty nine months in Bule Hora district, South Ethiopia. BMC Public Health 15: 41.

8. Amare D, Negesse A, Tsegaye B, Assefa B, Ayenie B (2016) Prevalence of Undernutrition and Its Associated Factors among Children below Five Years of Age in Bure Town, West Gojjam Zone, Amhara National Regional State, Northwest Ethiopia. Adv Public Health 2016.

9. Ermias A, Hussen M (2015)The Prevalence Of Stunting And Associated Factors Among Children Age 6-59 Months At Mizan-Aman Town, Bench Maji Zone, Snnpr Region, Ethiopia. Addis Ababa University.

10. Liben M, Abuhay T, Haile Y (2016) Determinants of Child Manutrition among Agro Pastorals in Northeastern Ethiopia: A cross sectional study. Health Sci J 10:17.

11. Solomon D, Amare W (2013) Magnitude and factors associated with malnutrition in children 6-59 months of age in pastoral community of Dollo Ado district, Somali region, Ethiopia. Sci J Public Health 1: 175-183.

12. Ma'alin A, Birhanu D, Melaku S, Tolossa D, Mohammed Y, Gebremicheal $\mathrm{K}$ (2016) Magnitude and factors associated with malnutrition in children 6-59 months of age in Shinille Woreda, Ethiopian Somali regional state: a cross-sectional study. BMC Nutrition 2: 44.

13. Fikadu T, Assegid S, Dube L (2014) Factors associated with stunting among children of age 24 to 59 months in Meskan district, Gurage Zone, South Ethiopia: a case-control study. BMC Public Health 14: 800.

14. Tamiru MW, Tolessa BE, Abera SF (2015) Under Nutrition and Associated Factors Among Under-Five Age Children of Kunama Ethnic Groups in Tahtay Adiyabo Woreda, Tigray Regional State, Ethiopia: Community Based Study. Int J Nutrition Food Sci 4: 277-288.

15. Girma W, Genebo T (2002) Determinants of Nutritional Status of Women and Children in Ethiopia. ORC Macro, Calverton, Maryland, USA.

16. Teshome B (2009) Magnitude and determinants of stunting in children under five years of age in food surplus region of Ethiopia: The case of West Gojam Zone. Eth J Health Dev 23: 98-106.

17. USAID (2014) Sustainable Undernutrition Reduction in Ethiopia (SURE). Ministry of Health.

18. CSA (2007) Demographic and Health Survey of Ethiopia.

19. WHO (2010) Nutrition Landscape Information System (NLIS) country profile indicators: interpretation guide. World Health Organization.

20. Turyashemererwa F (2009) Prevalence of early child hood malnutrition and influencing factors in peri urban areas of kabarole district, western Uganda African j food agri nut dev 9: 4.
21. Jiang Y, Su X, Wang C, Zhang L, Zhang X, et al. (2014) Prevalence and risk factors for stunting and severe stunting among children under three years old in mid-western rural areas of China. Child Care Health Dev 41: 45-51.

22. Kingsley R, Inder K, Bowe S, Jacobs J, Dibley M (2009) Prevalence and risk factors for stunting and severe stunting among under-fives in North Maluku province of Indonesia. BMC Pediatrics 9: 64.

23. Kinyoki DK, Berkley JA, Moloney GM, Kandala NB, Noor AM (2015) Predictors of the risk of malnutrition among children under the age of 5 years in Somalia. Public Health Nutr 18: 3125-3133.

24. Aline A (2012) Welch JR, Santos RV, Gugelmin SA, Coimbra CEA (2012) Nutritional status and growth of indigenous Xavante children, Central Brazil. Nutrition J 11: 3.

25. Kavosi E, Rostami ZH, Kavosi Z, Nasihatkon A, Moghadami M, et al. (2014) Prevalence and determinants of under-nutrition among children under six: a cross-sectional survey in Fars province, Iran. Int J Health Policy Manag 3: 71-76.

26. Nyaruhucha CNM, Mamiro PS, Kerengi AJ, Shayo NB (2006) Nutritional status of underfive children in a pastoral community in Simanjiro District, Tanzania. Tanzan Health Res Bull 8: 32-36.

27. Bhadoria AS (2006) prevalence of underweight, stunting and wasting among children in urban slum Delhi. Int J Nut Phar Neu Diseases 3: 323-324.

28. Dinesh K (2006) Influence of Infant-feeding Practices on Nutritional Status of Under-five Children. Indian J Pediatr 73: 417-421.

29. Ekpo UF, Omotayo AM, Dipeolu MA (2008) Prevalence of malnutrition among settled pastoral Fulani children in Southwest Nigeria. BMC Res Notes 1: 7 .

30. luc G, Mutegi K, Kipruto N (2015) Agro-pastoral and Mixed Farming Livelihood Zones, West Pokot County, Kenya. County Council of Research Science and Technology.

31. Ngianga B (2011) Malnutrition among children under the age of five in the Democratic Republic of Congo (DRC): does geographic location matter?. BMC Public Health 11: 261.

32. Wamani H, Astrøm AN, Peterson S, Tumwine JK, Tylleskär T (2007) Boys are more stunted than girls in Sub-Saharan Africa: a meta-analysis of 16 demographic and health surveys. BMC Pediatr 7:17.

33. Singh JP, Gupta SB, Shrotriya VP, Singh PN (2013) Study of Nutritional Status Among Under Five Children Attending Out Patient Department at A Primary Care Rural Hospital, Bareilly(UP). Sch J App Med Sci 1: 769-773.

34. Rathavuth H, Vinod M (2006) Effect of Wealth Inequality on Chronic Under-nutrition in Cambodian Children. J Health Popul Nutr 24: 89-99.

35. Paudel R, Pradhan B, Wagle RR, Pahari DP, Onta S R (2012) Risk Factors for Stuntng Among Children: A Community Based Case Control Study in Nepal. Kathmandu Univ Med J (KUMJ) 39:18-24.

36. Olagunju FI, Fakayode SB, Sola-Ojo FE (2011) Prevalence and Determinants of Malnutrition among Under-five Children of Farming Households in Kwara State, Nigeria. J Agric Sci 3: 3.

37. Benta A (2012) Effect of mother's education on child's nutritional status in the slums of Nairobi. BMC Pediatr 12: 80.

38. Rahman A (2016) Significant Risk Factors for Childhood Malnutrition: Evidence from an Asian Developing Country. Sci J Public Health 4: 16-27. 